\title{
Simultaneous Multidimensional Unfolding and Cluster Analysis: An Investigation of Strategic Groups
}

\author{
WAYNE DESARBO \\ Marketing and Statistics Departments, University of Michigan, School of Business \\ Administration, Ann Arbor, MI 48109-1234 \\ KAMEL JEDIDI \\ Colmmbia University \\ KAREL COOL \\ INSEAD \\ DAN SCHENDEL \\ Purdue University
}

Key words: Marketing Strategy, Multidimensional Scaling, Cluster Analysis, Strategic Groups

[June 1990, Revised August 1990]

\begin{abstract}
This paper develops a maximum likelihood based methodology for simultaneously performing multidimensional unfolding and cluster analysis on two-way dominance or profile data. This new procedure utilizes mixtures of multivariate conditional normal distributions to estimate a joint space of stimulus coordinates and $K$ ideal points, one for each cluster or group, in a $T$-dimensional space. The conditional mixture, maximum likelihood methodology is introduced together with an E-M algorithm utilized for parameter estimation. A marketing strategy application is provided with an analysis of PIMS data for a set of firms drawn from the same competitive industry to determine strategic groups, while simultaneously depicting strategy-performance relationships.
\end{abstract}

The majority of quantitative methodologies devised to investigate the underlying structure in various forms of two-way data (e.g., proximities, dominance/preference, profile data, etc.) have provided either continuous, spatial multidimensional scaling representations or discrete network clusterings. Some research has investigated the appropriateness of each of these two types of representations and their interrelationships for proximity data (see Pruzansky, Tversky, and Carroll, 1982; Arabie, Carroll, and DeSarbo, 1987). In many marketing applications, however, the researcher is often interested in applying both types of methodologies to the same set of two-way, two-mode data.

A number of alternatives are available in such situations. One could visually define clusters or groups from the spatial representation. However, independent 
results from Ling (1971), and Baker and Hubert (1976) raise serious concerns over the legitimacy of this practice. Another approach would be to first perform a spatial analysis, and then cluster the results. However, Gnanadesikan and Kettenring (1972), Chang (1983), and Dillon, Mulani, and Frederick (1989) have demonstrated that if one retains components with the larger eigenvalues, one may often fail to retain valuable information concerning distances or clusterings often contained in components with smaller eigenvalues. In addition, such two-step procedures (spatial analysis, then cluster subject coordinates) involve selecting: a specific spatial model, rotational scheme, method of normalizing subject coordinates, preprocessing for clustering, type of cluster analysis, a metric (in some cases), etc., which will most often produce different results! Finally, Carroll (1976) introduced "hybrid models" to fit to two-way proximity data. Such models combine the fitting of both tree structure(s) and continuous spatial components so that for a given two-way proximity data set, say, one might fit a tree structure and a two-dimensional Euclidean space. Since these are computed in a residual fashion, one cannot overlay or embed one analysis within the other. Another limitation concerns the problems of locally optimal solutions which haunts such "overfitting" procedures such as these, especially with the use of exterior penalty function methods. In addition, such procedures become computationally unfeasible if the number of objects analyzed is much greater than 30 or so. Finally, such hybrid models are applicable only to two-way proximity data and not to dominance/preference or profile data.

This paper develops a maximum likelihood based methodology for simultaneously performing multidimensional unfolding analysis and cluster analysis on a given set of two-way dominance/preference or profile data. This new methodology utilizes mixtures of multivariate conditional normal distributions to estimate an unfolding model joint space of stimulus (column) coordinates and $K$ ideal points, one for each cluster or group, in a $T$-dimensional space. The next section presents a brief review of the literature on strategic groups - the selected area of application. The following section presents the technical structure of the model as well as a brief description of the E-M algorithm devised for estimating the model's parameters. Finally, a marketing strategy application is presented concerning the analysis of PIMS data for a designated industry to define strategic groups.

\section{Strategic group research}

Since the early seventies, several perspectives and methods have been developed to evaluate the impact of business strategy on firm performance. A recurring concern in many of these studies is the problem of simultaneously evaluating the impact of strategy (conduct) attributes on firm performance, on the one hand, and assessing the degree and consequences of strategy differences (asymmetry) 
among firms on the other. A central theme in this type of research is that strategic choices have identifiable consequences for firm performance. Since some competitive strategies are more appropriate to particular environmental conditions than others, certain strategy types should lead to superior performance. Thus, within a given industry, some groups of firms with a particular strategic conduct pattern should outperform other such "strategic groups" following other strategic patterns (see Porter, 1979, 1980; Caves and Porter, 1977).

Recently, several studies have found that firms pursuing the same strategy type or that are from the same strategic group do not necessarily achieve similar profitability results (see McGee and Thomas, 1986; White, 1986; Cool and Schendel, 1987, 1988). As one explanation for this differential performance achievement, Rumelt (1984) has argued that the same factors that protect industries from entry, or group members from intra-industry entry (mobility barriers), also protect individual firms from imitation (isolating mechanisms).

Another issue in strategic group research concerns the methodologies employed in these studies. Despite the large number of studies that have tried to operationalize the strategic group concept, progress in the application or development of methodologies has been modest. The necessity of tailoring analyses to a particular industry context has introduced a substantial variety of interpretations of the concept in terms of strategy definitions used. Furthermore, given the (highly) judgmental nature of applied methods used for grouping, primarily various different clustering methods, a further source of "noise" is introduced. Comparisons between studies become exceedingly difficult owing to either conceptual ambiguity or methodological variations, or both. Strategic groups derived on the same set of data often differ with respect to the type of clustering utilized (see Harrigan, 1985).

Finally, the question of multiple performance objectives needs to be confronted. While it is typically assumed that firms are profit maximizing entities, it is conceivable that at least some firms pursue tradeoffs among a set of performance objectives (e.g., market position, growth, and profitability). Of course, one can try to compare groups of firms along several performance dimensions (see Schendel and Patton, 1978 for one such attempt). Yet, if firms pursue different objectives, such comparisons are not necessarily meaningful. Methods would need to be developed to relate the objectives pursued with the actions (strategies) taken.

The present paper purposes an alternative approach for deriving strategic groups from empirical data. The proposed methodology will attempt to

a. Estimate strategy-performance relationships;

b. Derive strategic groups and respective firm membership;

c. Allow for multiple firm membership in different strategic groups which can accommodate differential performance among the members of the same strategic group. 


\section{The proposed methodology}

\subsection{Model structure}

We propose a new methodology which simultaneously performs both multidimensional scaling and cluster analysis. Given our application will be in the area of strategic group determination, we will describe our procedure in these related terms. Three aspects of the strategic group-performance relationship are dealt with simultaneously. First, a $T$-dimensional multidimensional scaling space of strategy attributes and/or performance variables is derived which depicts the interrelationships between performance attributes and strategy attributes (as in Day, DeSarbo, and Oliva, 1987). Second, locations of clusters or groups of similar firms are estimated in this same space. This reveals how such strategic groups are defined and how they differ with respect to the underlying dimensions. Finally, group membership for each firm is estimated via the posterior probability of each firm belonging to any given strategic group, giving insight into patterns of multiple group membership.

Let:

$$
\begin{aligned}
i & =1, \ldots, \text { I firms or SBU's; } \\
j & =1, \ldots, \text { J strategy and performance attributes; } \\
k & =1, \ldots, \mathrm{K} \text { strategic groups; } \\
t & =1, \ldots, \mathrm{T} \text { dimensions; } \\
\Delta_{i j} & =\text { the value of strategy/performance variable } j \text { for firm } i \\
X_{j t} & =\text { the } t \text { th coordinate for variable } j \\
Y_{k t} & =\text { the } t \text { th coordinate for strategic group } k ; \\
W_{k t} & =\text { the importance or salience of dimension t for strategic group } k ; \\
C_{k} & =\text { an additive constant for strategic group } k ; \\
\sum_{\mathrm{k}} & =\text { a } J \times J \text { variance-covariance matrix for strategic group } k .
\end{aligned}
$$

It is assumed that the row vector $\Delta_{i}$ of dimension $\mathbf{J}$ has a probability density function which can be modeled as a finite mixture of the following conditional distributions:

$$
\mathrm{G}\left(\Delta_{\mathrm{i}} ; \underset{\sim}{\lambda}, \underset{\sim}{\mathrm{X}}, \underset{\sim}{\mathrm{Y}}, \underset{\sim}{\Sigma}, \underset{\sim}{\mathrm{C}}, \underset{\mathrm{k}=1}{\mathrm{~W}}\right)=\sum_{\mathrm{k}} \mathrm{f}_{\mathrm{ik}}\left(\Delta_{\mathrm{i}} \mid \underset{\sim}{\mathrm{X}}, \underset{\mathrm{Y}_{\mathrm{k}}}{\mathrm{C}_{\mathrm{k}}}, \underset{\mathrm{W}_{\mathrm{k}}}{\Sigma_{\mathrm{k}}}\right),
$$


where:

$$
\begin{aligned}
\underset{\sim}{\lambda}= & \left(\lambda_{1}, \lambda_{2}, \ldots, \lambda_{\mathrm{k}-1}\right) \text { are the K-1 independent mixing proportions } \\
& \text { of the finite mixture such }
\end{aligned}
$$

that:

$$
\begin{aligned}
& 0 \leq \lambda_{\mathrm{k}} \leq 1 \text {, with } \lambda_{\mathrm{K}}=1-\sum_{\mathrm{k}=1}^{\mathrm{K}-1} \lambda_{\mathrm{k}} \text {; } \\
& \underset{\sim}{X}=\left(\left(X_{\mathrm{jt}}\right)\right), \\
& \underline{Y}=\left(\left(Y_{k t}\right)\right) \text {, } \\
& \underline{Y}_{\mathrm{k}}=\text { the } 1 \times \mathrm{T} \text { row vector of coordinates of the } k \text { th } \\
& \text { row (strategic group) of } \underline{Y} \text {, } \\
& \underline{W}=\left(\left(W_{\mathrm{k}}\right)\right) \text {, } \\
& \underline{\mathrm{W}}_{\mathrm{k}}=\text { the } 1 \times \mathrm{T} \text { row vector of salience weights of the } k \text { th } \\
& \text { row (strategic group) of } \underset{\sim}{W} \text {, } \\
& \mathrm{C}=\mathrm{C}_{1}, \mathrm{C}_{2}, \ldots, \mathrm{C}_{\mathrm{K}} \text {, } \\
& \underline{\Sigma}^{\prime}=\left(\Sigma_{1}, \Sigma_{2}, \ldots, \Sigma_{\mathrm{K}}\right) .
\end{aligned}
$$

The distribution for each $\mathrm{f}_{\mathrm{ik}}$ is specified as a conditional (nonlinear) multivariate normal:

$$
\begin{aligned}
& \mathrm{f}_{\mathrm{ik}}\left(\underline{\sim}_{\mathrm{i}} \mid \underset{\sim}{\mathrm{X}}, \underline{\mathrm{Y}}_{\mathrm{k}}, \mathrm{C}_{\mathrm{k}}, \underline{\mathrm{W}}_{\mathrm{k}}, \underline{\Sigma}_{\mathrm{k}}\right)
\end{aligned}
$$

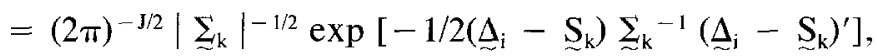

where:

$$
\begin{aligned}
\underline{S}_{k} & =\left(S_{1 k}, S_{2 k}, \ldots, S_{j k}\right), \\
S_{j k} & =\sum_{t=1}^{T} W_{k t}\left(X_{j t}-Y_{k t}\right)^{2}+C_{k} .
\end{aligned}
$$

Expression [4] represents a weighted Euclidian distance formulation (see Carroll, 1980 ) between strategic group $k$ and (strategy or performance) variable $j$ in the 
derived Euclidian space. More specifically, the "closer" a particular strategy and/ or performance variable is to a strategic group location, the higher the value of that variable is predicted for that strategic group. This is conceptually equivalent to the notion of distance in the strategy map concept of Day, DeSarbo, and Oliva (1987) in their application of the DeSarbo and Rao $(1984,1986)$ GENFOLD2 procedure. However, our methodology determines the locations and behavior for strategic groups, and not that of individual firms. In addition, the present methodology is stochastic, whereas GENFOLD2 is deterministic.

The "full" model thus estimates the coordinates of the J strategy and performance variables $(X)$, the coordinates of the strategic groups $(Y)$, the coordinates of the strategic group weights (W), the covariance matrices $\left(\Sigma_{k}\right)$, and the additive constants $\left(\mathrm{C}_{k}\right)$. The $\underset{\sim}{\mathrm{X}}$ and $\underset{\mathrm{Y}}{\mathrm{Y}}$ are plotted in a joint $\mathrm{T}$-dimensional space indicating (by these distance notions) the relationships between the derived strategic groups and the strategy and performance variables. The ${\underset{\sim}{k}}_{k}$ indicate which dimensions are more salient for the $\mathrm{k}^{\text {th }}$ strategic group. The $\Sigma_{k}$ gives the estimated covariance structure among the strategy and performance variables for strategic group $\mathrm{k}$. DeSarbo, Howard and Jedidi (1991) used a similar framework for understanding consumer preferences, where $S_{\mathrm{jk}}$ was specified as a scalar-products model rather than a weighted distance model.

Given a sample of I independent firms, one can thus form a likelihood expression:

$$
L=\prod_{i=1}^{1}\left[\sum_{k=1}^{K} \lambda_{k}(2 \pi)^{-J / 2}\left|\Sigma_{k}\right|^{-1 / 2} \exp \left[-1 / 2\left(\underline{\Delta}_{i}-\underline{S}_{k}\right) \underline{\Sigma}_{k}^{-1}\left(\underline{\Delta}_{i}-\underline{S}_{k}\right)^{\prime}\right]\right]
$$

or,

$$
\ln \mathrm{L}=\sum_{\mathrm{i}=1}^{1} \ln \left[\sum_{\mathrm{k}=1}^{\mathrm{K}} \lambda_{\mathrm{k}} \mathrm{f}_{\mathrm{ik}}\left(\Delta_{\mathrm{i}} \mid \underset{\sim}{\mathrm{X}},{\underset{\sim}{\mathrm{k}}}_{\mathrm{k}}, \mathrm{C}_{\mathrm{k}},{\underset{\sim}{\mathrm{W}}}_{\mathrm{k}}, \underset{\sim}{\mathrm{k}}\right)\right]
$$

Given $\underset{\sim}{\Delta}, \mathrm{T}$, and $\mathrm{K}$, one wishes to estimate $\underset{\sim}{\mathrm{\Sigma}}, \underset{\sim}{\mathrm{X}}, \underset{\sim}{\mathrm{Y}}, \underset{\sim}{\mathrm{C}}$, and $\mathrm{W}$, in the "full model" so as to maximize expressions [5] or [6], given the conditions specified in equation [2].

\subsection{Identification of group membership}

Once estimates of $\lambda, \Sigma, X, Y, C$, and $W$ are obtained for any iteration of the maximum likelihood procedure, one can assign each firm $i$ to each strategic group $\mathrm{k}$ via the estimated posterior probability (applying Bayes' rule), providing a "fuzzy" clustering: 


$$
\hat{\mathrm{P}}_{\mathrm{ik}}=\frac{\hat{\lambda}_{\mathrm{k}} \hat{\mathrm{f}}_{\mathrm{ik}}\left(\underline{\Delta}_{\mathrm{i}} \mid \underline{X}, \underline{\mathrm{Y}}_{\mathrm{k}}, \mathrm{C}_{\mathrm{k}}, \underline{W}_{\mathrm{k}}, \underline{\Sigma}_{\mathrm{k}}\right)}{\sum_{\mathrm{k}=1}^{\mathrm{K}} \hat{\lambda}_{\mathrm{k}} \hat{\mathrm{f}}_{\mathrm{ik}}\left(\Delta_{\mathrm{i}} \mid \underline{X}, \underline{\sim}_{\mathrm{k}}, \mathrm{C}_{\mathrm{k}}, \underline{W}_{\mathrm{k}}, \underline{\sim}_{\mathrm{k}}\right)}
$$

where $\sum_{\mathrm{k}=1}^{\mathrm{K}} \hat{\mathrm{P}}_{\mathrm{ik}}=1$, and $0 \leq \hat{\mathrm{P}}_{\mathrm{ik}} \leq 1$.

This particular feature allows for the flexibility of modeling situations where the members of a particular derived strategic group have different performance outcomes by allowing individual firms to be fractional members of multiple strategic groups. One could form partitions, if desired, by simply assigning firm $i$ to the strategic group whose $\hat{\mathrm{P}}_{\mathrm{ik}}$ was highest. Thus, our methodology will simultaneously estimate the joint space of the variables and strategic group locations, as well as the compositions of the strategic groups themselves. An ExpectationMaximization (E-M) algorithm (Dempster, Laird, and Rubin, 1977) is utilized for parameter estimation. It alternates between using analytical expressions for estimating $\lambda, \underset{\sim}{\mathrm{P}}$, and $\underset{\sim}{\Sigma}$ (see DeSarbo, et al, 1991), and a conjugate gradient procedure for $W, \underset{\sim}{\mathrm{X}}, \underset{\mathrm{C}}{\mathrm{N}}$, and $\underset{\mathrm{Y}}{\mathrm{P}}$.

\subsection{Tests for $T$ and $K$}

How does one identify the "best" values for T and K? One obvious way of approaching the problem is to use the likelihood ratio test statistic to test for the smallest values of $\mathrm{T}$ and $\mathrm{K}$ compatible with the data. However, according to Hartigan (1977), Brock (1985), and McLachlan and Basford (1988), regularity conditions do not hold for differences in $(-2 \ln \mathrm{L})$ to have its usual asymptotic null distribution of chi-squared with degrees of freedom equal to the difference in the number of parameters in the two hypotheses. Wolfe (1970), and Hartigan and Hartigan (1985) consider the use of a correlation factor $r$, via $(-2 r \ln L)$, but disagree as to what value of $r$ is appropriate. More recently, Bozdogan and Sclove (1984) have proposed using Akaike's (1974) information criterion (AIC) for the choice of the number of groups in such mixture clustering models. In our methodology, one would select $\mathrm{K}$ and $\mathrm{T}$ which minimize:

$$
\operatorname{AIC}(K, T)=-2 \ln L+2 N(K, T),
$$

where $\mathrm{N}(\mathrm{K}, \mathrm{T})$ is the number of independent parameters for the estimated full model:

$$
\mathrm{N}(\mathrm{K}, \mathrm{T})=2 \mathrm{KT}+\mathrm{JT}+\mathrm{K}[[\mathrm{J}(\mathrm{J}-1)] / 2]+\mathrm{K}-1-2 \mathrm{~T}
$$


While this AIC test will be utilized to select appropriate values of $\mathrm{K}$ and $\mathrm{T}$, this criterion relies essentially on the same regularity conditions needed for differences in $(-2 \ln \mathrm{L})$ to have its usual asymptotic distribution under the null-hypothesis (see Titterington, Smith and Makov, 1985; Bozdogan, 1987; and Sclove, 1987). We therefore recommend the inspection of other goodness of fit measures such as a variance-accounted for (VAF) measure between $\underset{\sim}{\Delta}$ and $\underset{\sim}{\hat{\Delta}}=\sum_{\mathrm{k}=1}^{K} \hat{\mathrm{P}}_{\mathrm{ik}} \underline{\sim}_{\mathrm{k}}$ across all $\mathrm{i}$, for values of $\mathrm{T}$ and $\mathrm{K}$, as is done in traditional metric multidimensional scaling and "least-squares" clustering approaches (see Arabie, Carroll and DeSarbo, 1987).

\section{Empirical analysis}

\section{I. Sample and variable selection}

A sample of fourteen firms was drawn from the PIMS data base by Day, DeSarbo, and Oliva (1987). To limit cross-sectional heterogeneity, firms were drawn from a single four-digit SIC code. The industry selected can be described as a fragmented and mature industrial supply industry. Table 1 lists the ten variables selected to describe strategy in this industry. The performance measures used are given in Table 2. In all, ten strategy measures and eight performance indicators were selected by these authors and will thus be used here. Therefore, $\Delta$ consists of a matrix of 14 firms and 18 strategy and performance variables measured on these firms. Our goal is to simultaneously describe the performance-strategy relationships and derive strategic groups.

\subsection{Group identification}

The traditional clustering approach. Strategic group research may be affected in non-trivial ways by several, sometimes arbitrary, choices abut the particular type of cluster analysis performed. Included in the factors which are likely to influence the outcome (Anderberg, 1973) are: the type of cluster analysis selected (partitioning, overlapping, fuzzy hierarchical, etc.), the choice of the specific algorithm/ model within each type of cluster analysis (for example, in hierarchical models of clustering, there are agglomerative and divisive methods, and within each of these there are often several different models, e.g., minimum, average, or maximum link methods for agglomerative hierarchical clustering), the selection of the distance metric, the preprocessing of the variables, etc. To evaluate whether an observed strategic group structure may be an artifact of a particular clustering used, several types of cluster analyses were conducted on this PIMS data. Six different hierarchical clustering analyses (single linkage, complete linkage, average linkage, 
Table 1. Strategy measures

\begin{tabular}{|c|c|}
\hline Term & Definition \\
\hline \multicolumn{2}{|l|}{ Differentiation: } \\
\hline Relative Product Quality (A) & $\begin{array}{l}\text { Percentage volume from superior products } \\
\text { minus percentage from inferior products. }\end{array}$ \\
\hline Relative Price (B) & $\begin{array}{l}\text { Weighted average of three largest competitors } \\
=100 \% . \text { Example: If this business's prices } \\
\text { average } 5 \% \text { above those of leading } \\
\text { competitors than the value of } 105 \% \text {. }\end{array}$ \\
\hline Relative Advertising (C) & $\begin{array}{l}\text { Relative to the three largest competitors, did } \\
\text { this business spend from "much more" to } \\
\text { "much less" on advertising using a five- } \\
\text { point ordinal scale? }\end{array}$ \\
\hline Relative Sales Force (D) & $\begin{array}{l}\text { Relative to the three largest competitors, did } \\
\text { this business spend from "much more" to } \\
\text { "much less" percentage of its sales on sales } \\
\text { forces effort using a five-point ordinal } \\
\text { scale? }\end{array}$ \\
\hline Value added/employee (E) (productivity) & $\begin{array}{l}\text { Value added divided by the ratio of net sales } \\
(+ \text { lease revenues }) \text { to sales per employee } \\
(\$ 1000) \text {. }\end{array}$ \\
\hline \multicolumn{2}{|l|}{ Efficiency: } \\
\hline Process R\&D/Sales $(F)$ & $\begin{array}{l}\text { Indicates all expenses for improving the } \\
\text { efficiency of the manufacturing and } \\
\text { distribution. The figure is disguised in the } \\
\text { database by a factor unique to each } \\
\text { business. }\end{array}$ \\
\hline Receivables/Sales $(G)$ & $\begin{array}{l}\text { Average receivables for the year, net of } \\
\text { allowances for bad debts. }\end{array}$ \\
\hline $\begin{array}{l}\text { Capital Intensity (Gross Book (H) Value } \\
\text { P\&E/Sales) }\end{array}$ & $\begin{array}{l}\text { Gross book value of plant and equipment } \\
\text { divided by new sales ( }+ \text { lease revenues). }\end{array}$ \\
\hline \multicolumn{2}{|l|}{ Scale/Scope: } \\
\hline Relative Customer Size (I) & $\begin{array}{l}\text { Breadth of this business's served market, } \\
\text { relative to the weighted average of the three } \\
\text { largest competitors on a three-point ordinal } \\
\text { scale from "Narrower Than Competitor" to } \\
\text { "Broader than Competitor." }\end{array}$ \\
\hline Value Added/Sales (J) Vertical Integration & $\begin{array}{l}\text { Value added divided by net sales ( }+ \text { lease } \\
\text { revenues). }\end{array}$ \\
\hline
\end{tabular}

Source: Modified from Day, DeSarbo, and Oliva (1987).

centroid method, median method, and Ward's (1963) procedure) were performed (Wilkinson, 1988) for each of two different distance metrics (normalized Euclidian distance and one minus the pearson correlation coefficient). A K-MEANS partitioning method for 2 to 6 clusters was also performed (Hartigan, 1975).

A sample view of the sensitivity of cluster results to the choice of the specific cluster procedure can be seen in Table 3. This table gives the composition for a five-cluster solution for the Ward (1963), complete linkage, and the K-MEANS 
Table 2. Performance measures

\begin{tabular}{|c|c|}
\hline Term & Definition \\
\hline Market Share (1) & Percentage market share for this business. \\
\hline Change in Market Share $(\%)(2)$ & $\begin{array}{l}\text { The sum of the absolute values if the yearly } \\
\text { changes in percentage market to share for: } \\
\text { this business, largest competitor, } 2 \text { nd } \\
\text { largest competitor, 3rd largest competitor; } \\
\text { divided by number of years in the span. }\end{array}$ \\
\hline Relative Market Share (3) & $\begin{array}{l}\text { Percent market share for this business divided } \\
\text { by percentage market share for top three } \\
\text { competitors. }\end{array}$ \\
\hline ROI-Return on Investment (4) & $\begin{array}{l}\text { Net Operating Income divided by average } \\
\text { investment (book value). }\end{array}$ \\
\hline ROS-Return on Sales (5) & $\begin{array}{l}\text { Net income divided by net sales ( }+ \text { lease } \\
\text { revenues). }\end{array}$ \\
\hline Cash Flow/Revenue (6) & $\begin{array}{l}\text { Net income times }(0.5) \text { minus average } \\
\text { investment (year } \mathrm{N} \text { ) minus average } \\
\text { investment (year } \mathrm{N}-\mathrm{I}) \text {; divided by net sales } \\
\text { (+ lease revenues). }\end{array}$ \\
\hline Cash Flow/Investment (7) & $\begin{array}{l}\text { Net income times }(0.5) \text { minus average } \\
\text { investment (year } \mathrm{N} \text { ) minus average } \\
\text { investment (year } \mathrm{N}-\mathrm{I} \text { ); divided by } \\
\text { average investment. }\end{array}$ \\
\hline Real Sales Growth $(\%)(8)$ & $\begin{array}{l}\text { Percentage change found by dividing net sales } \\
(+ \text { lease revenues) by percentage index of } \\
\text { prices }(1973=100 \%) .\end{array}$ \\
\hline
\end{tabular}

Source: Adapted from Day, DeSarbo, and Oliva (1987).

clusterings. (Many of the results obtained for all the methods used supported a five cluster solution; some also did not). Although there are some similarities, especially between the solutions from K-MEANS and complete linkage, rather dramatically different results are obtained across these different methods. (A comparative inspection of the resulting dendrograms from the various hierarchical procedures also revealed rather dramatically different results). As has been well documented in the classification literature (e.g., Anderberg, 1973), different clustering methods often do indeed produce sometimes strikingly different results in terms of cluster structure and membership.

Our approach. The column standardized $\Delta$ was analyzed via the our methodology with the number of dimensions, $\mathrm{T}$, and the number of groups, $\mathrm{K}$, ranging from 1 to 6 . To make a selection among the various solutions, Akaike's (1974) information criterion (AIC) and a variance accounted-for (VAF) statistic was used. Based upon an inspection of these heuristics and resulting interpretation, a solution of $\mathrm{T}=4$ and $\mathrm{K}=5$ with $\mathrm{\Sigma}_{\mathrm{k}}=\mathrm{I}$ provided the most parsimonious description of the structure in the data $(\mathrm{AIC}=761.08$; $\mathrm{VAF}=0.631)$. Using the estimated posterior probabilities, $\hat{\mathrm{P}}_{\mathrm{ik}}$, as described above, the association of each 
Table 3. Five strategic groups derived by three traditional cluster analyses

\begin{tabular}{llll}
\hline & Ward's method & Complete linkage & K-MEANS \\
\hline Group 1 & $2,4,6,14$ & 4,14 & 4,14 \\
Group 2 & 1,5 & 1 & 1 \\
Group 3 & $10,11,12$ & $3,8,9,10,11,12,13$ & $2,3,5,6,10,11,12$ \\
Group 4 & $3,7,9$ & 7 & 7 \\
Group 5 & 8,13 & $2,5,6$ & $8,9,13$ \\
\hline
\end{tabular}

Table 4. The P matrix of strategic group membership

\begin{tabular}{llllll}
\hline & \multicolumn{5}{c}{ Strategic Group } \\
\cline { 2 - 6 } Firm & $\mathrm{a}$ & $\mathrm{b}$ & $\mathrm{c}$ & $\mathrm{d}$ & $\mathrm{e}$ \\
\hline 1 & 0.000 & 0.000 & 0.000 & 0.999 & 0.001 \\
2 & 0.999 & 0.000 & 0.000 & 0.001 & 0.000 \\
3 & 0.981 & 0.000 & 0.001 & 0.001 & 0.017 \\
4 & 0.001 & 0.999 & 0.000 & 0.000 & 0.000 \\
5 & 0.999 & 0.001 & 0.000 & 0.000 & 0.000 \\
6 & 0.993 & 0.006 & 0.000 & 0.001 & 0.000 \\
7 & 0.000 & 0.000 & 0.999 & 0.000 & 0.001 \\
8 & 0.005 & 0.000 & 0.000 & 0.000 & 0.995 \\
9 & 0.891 & 0.000 & 0.000 & 0.000 & 0.109 \\
10 & 0.999 & 0.001 & 0.000 & 0.000 & 0.000 \\
11 & 0.999 & 0.000 & 0.001 & 0.000 & 0.000 \\
12 & 0.998 & 0.000 & 0.000 & 0.000 & 0.002 \\
13 & 0.010 & 0.000 & 0.000 & 0.000 & 0.990 \\
14 & 0.001 & 0.999 & 0.000 & 0.000 & 0.000 \\
Size: & 8 & 2 & 1 & 1 & 2 \\
Members: & $(2,3,5,6,9,10,11,12)$ & $(4,14)$ & $(7)$ & $(1)$ & $(8,13)$ \\
\hline
\end{tabular}

firm to each strategic group was evaluated. This estimated membership is given in Table 4. Note the comparison of these results with the cluster outcomes listed in Table 3. First, somewhat similar memberships can be observed between those derived from the K-MEANS procedure and the classification results based on the estimated posterior probabilities, $\hat{\mathrm{P}}_{\mathrm{ik}}$. With the exception of Firm 9 , the KMEANS and our method lead to similar clustering results (once you round the $\hat{\mathrm{P}}_{\mathrm{ik}}$ to 0 or 1). In contrast, the derived membership based on Ward's procedure suggests a completely different picture. Since Ward's minimum variance criterium has been one of the most popular cluster routines in Marketing and past strategic group research (see Dess and Davis, 1984), this finding is of particular interest.

We also mentioned that strategic group membership should not be thought of as exclusive membership to one group versus another. Since conduct similarity is a matter of degree rather than a discrete phenomenon, some firms may have char- 
acteristics of different strategic groups. Hence the need for a method which can assess fuzzy or probabilistic membership. The estimated posterior probabilities $\hat{\mathrm{P}}_{\mathrm{ik}}$, of each firm $\mathrm{i}$ belonging to a particular group $\mathrm{k}$ give insight into the degree of membership exclusivity. For the sample considered here, there appears to be little ambiguity about group membership; most $\hat{\mathrm{P}}_{\mathrm{ik}}$ are close to 0.0 and 1.0 . Obviously, extreme fuzzy group membership may not be appropriate in all analyses. The usefulness of this information may depend, for example, on the characteristics of the industry studied. In faster changing environments where the assumptions of distinctive and stable conduct differences are less tenable, group membership tends to be more unstable and estimates of fuzzy group membership become important. In contrast, in more stable environments, such analysis may reveal relatively little additional information. The current sample is a case in point. In a mature industry, one generally expects more stable group structure and membership patterns. Therefore, one should find that the incidence of fuzzy group membership is relatively low, as is exactly what is observed for the present sample.

However, the case of Firm 9 is instructive as it illustrates the potential of our procedure to deal with fuzzy membership. While the posterior probability $\hat{\mathrm{P}}_{\mathrm{ga}_{\mathrm{a}}}=$ 0.891 suggests that Firm 9 is best associated with strategic group location a, it also has a probability of 0.109 to be associated with location e. In other words, this firm may be considered as having different fractional membership in two different strategic groups. If such is the case, one would expect that its membership across the different cluster solutions would be ill-defined; i.e., one should find that Firm 9 is classified in different groups for different cluster algorithms. In fact, Table 3 confirms this. Across the three different cluster results reported, Firm 9 can be found in three different clusters. Thus, our approach offers the potential to deal with two important drawbacks of cluster analysis: the selection of the number of clusters, and the determination of potentially fuzzy cluster membership.

\subsection{Strategy-performance relationships}

Figure 1 depicts the four dimensions in a unidimensional, "shoestring" fashion. Upper case letters A-J indicate the strategy measures shown in Table 1; the integers 1-8 represent the eight performance indicators from Table 2, and lowercase letteres a-e depict the derived strategic groups and their locations.

3.3.1. Definition of dimensions. The derived dimensions here are interpreted, as in most other spatial models, in terms of those items which lie at the extreme positive and negative poles of the dimensions. As can be seen in Figure 1, the four derived dimensions align nearly perfectly with four major performance constructs from Table 2: dimension I reflects profitability with ROI (4) and ROS (5) having 
Unidimensional Plots

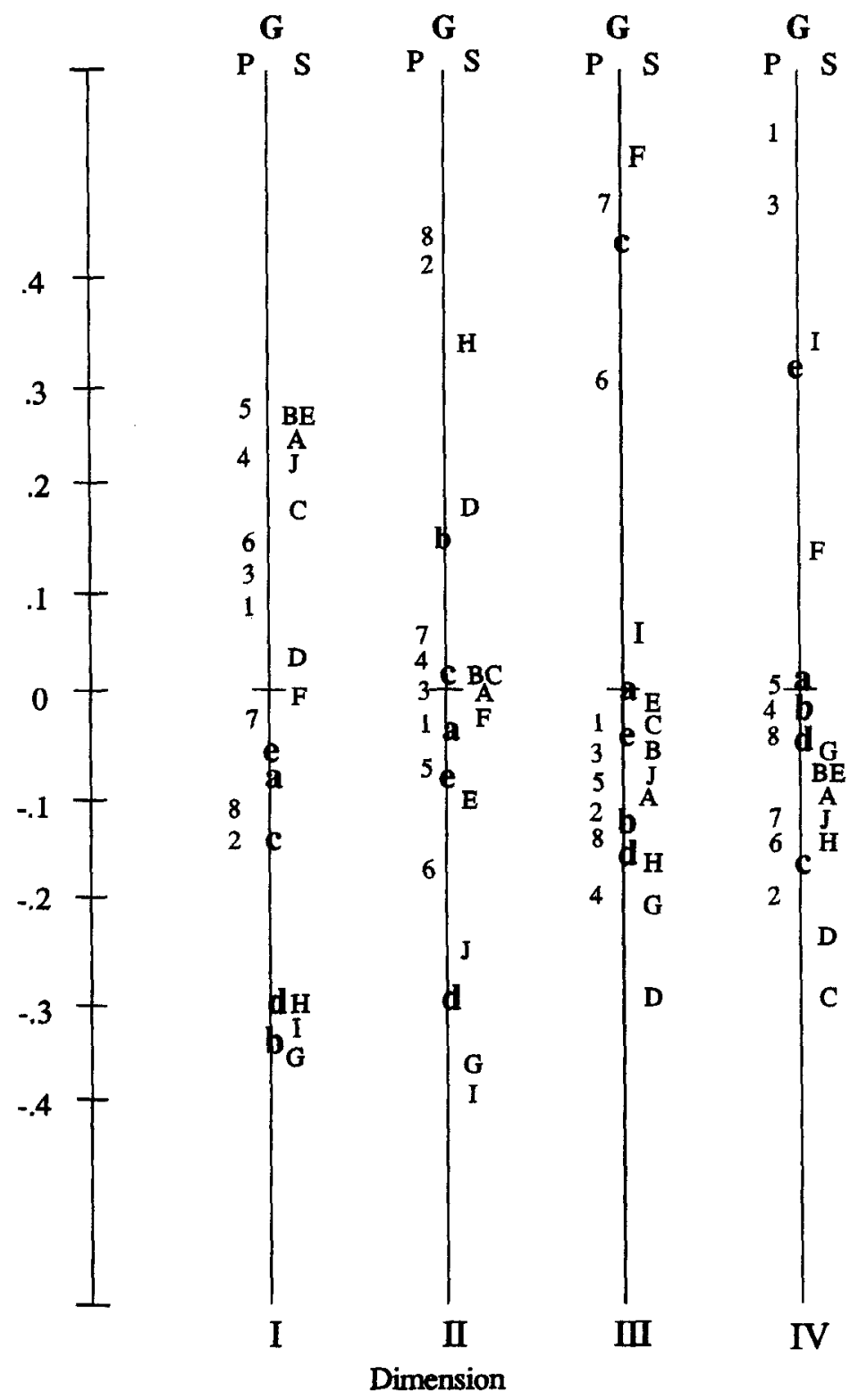

I = Profitability, II = Growth, III = Cash Flow,

IV $=$ Market Position. $\mathbf{G}=$ Groups (a-e).

P-Performance Measures (1-8). S = Strategy attributes (A-J)

Figure 1. Strategy-performance relationships. 
high positive coordinate locations. Dimension II can be defined as growth where Market Share Change (2) and Real Sales Growth (8) have highly positive locations. Dimension III can be termed cash flow as Cash Flow/Revenue (6) and Cash Flow/Investment (7) load highly positive on this dimension. Finally, dimension IV reflects market position where Market Share (1) and Relative Market Share (3) are clearly located at the positive end of the dimension.

3.3.2. Performance-strategy relations. In Figure 1, the relationships of the strategy attributes A-J to the derived dimensions (profitabillity, growth, cash flow and market position) are indicated by the extension of each of the strategy attributes on each of the four derived dimensions. The closer (further) the proximity of the strategy variable and performance attribute, the stronger the predicted positive (negative) relationship between the pairing.

Concerning the first dimension, profitability, higher returns are associated with higher product quality (A) for which a higher relative price $(\mathbf{B})$ can be charged. Connected with this higher price and higher quality are the higher value added measures $(\mathbf{E}, \mathbf{J})$. On the negative side, lower levels of capital intensity (H) and credit policy (G) adversely affect profitabililty. Note, the negative impact on profitability of customer size (I) where, for a mature industrial supplier, customer bargaining power of larger customers takes its toll. Finally, the opposite locations of the profitability attributes $(\mathbf{4}, \mathbf{5})$ and the growth attributes $(\mathbf{2}, \mathbf{8})$ on Dimension I suggest that is a trade-off between profitability and growth.

Regarding the second dimension, growth, higher rates of growth are associated with capital intensity $(\mathbf{H})$. Negatively related with this growth dimension are: 1) relative customer size (I), where smaller customers cannot contribute to growth as strongly as larger customers; 2) credit policy (G); and, 3) value added/sales (J), which implies higher margins are not helpful in increasing market share. The performance variables that are highly positive and give rise to this dimension are real sales growth (8) and change in market share (2), both obvious indicators of growth.

Concerning the third dimension, cash flow, higher cash flow as a performance outcome appears to be achieved through an efficiency focus that can result from heavier emphasis of process $\mathrm{R} \& \mathrm{D}(\mathbf{F})$. On the other hand, investments in sales force $(\mathbf{D})$, customer credit $(\mathbf{G})$ and capital equipment $(\mathbf{H})$, perhaps required by outcomes of process $\mathrm{R} \& \mathrm{D}$, all adversely influence cash flow. Here, too, a tradeoff is seen in terms of performance outcomes, as growth performance attributes, real sales growth (8), and profitability, ROS (4), are sacrificed whenever cash flow performance $(6,7)$ is sought.

Finally, with respect to the fourth dimension, market position, share of market is related positively to relative customer size (I). Clearly, larger customers help volume and therefore market share (1). Market position is negatively related to relative advertising $(\mathbf{C})$ and sales force investments $(\mathbf{D})$ that do not exceed industry averages. The tradeoff tendency observed here is market position $(\mathbf{1}, \mathbf{3})$ for cash flow (6) and changes in market share (2). 
3.3.3. Goal asymmetry. The question of how each group performs on each of the dimensions can be inferred from Figure 1. Clearly, group $\mathbf{d}$ is underperforming on all dimensions. Since group b also scores low on most dimensions, it can be inferred that the "low price/quality" strategy in this business is not rewarding, except to achieve high growth for group b. Further, it can be concluded that the "me too" strategy of group a leads to the same type of performance: an average outcome across all attributes. This outcome for group a stands in contrast with the performance of groups $\mathbf{c}$ and $\mathbf{e}$. While group $\mathbf{c}$ stands out for its performance in terms of cash flow generation, it is also noteworthy for its "weak" market position. Group c seems to be willing to trade market share for cash flow, perhaps in some form of a liquidation strategy. Similarly, while the "high price/quality" approach of group e appears to command a strong market position and the strongest profitability, it performs only modestly in terms of growth and cash flow generation.

How groups attach differential importance to each of the dimensions can be inferred from Figure 2 which maps the salience weights $W_{k 1}$ of each group on each dimension. Some clear patterns can be observed. Group a, which is also the largest group, apparently has a policy of balanced performance across the entire performance spectrum. This clearly stands in contrast with the salience weights of group c. Its superior performance in terms of cash flow reflects the importance it attaches to this performance dimension (see Figures 1 and 2). Similarly, the weak market position of group $\mathbf{c}$ is a reflection of the apparent lack of concern with market share.

Groups $\mathbf{b}$ and $\mathbf{d}$, with their strategic emphasis on low price/quality, show a remarkably similar set of importance weights in Figure 2. Both seem to have embarked on a growth strategy and do not seem to be interested in either cash flow or market position performance. However, while $\mathbf{b}$ shows some realization of the importance it places on growth (Figure 1), group d simply appears to be a loser on all dimensions, regardless of importance, perhaps owed to poor execution of the strategy relative to group $\mathbf{b}$.

Group e shows a strong preference for market position performance and has secured this position as shown in Figure 1. In this respect, it is similar to groups $\mathbf{b}$ and $\mathbf{c}$ in that it has shown itself collectively as able to execute a strategy that will pursue the performance dimension to which it attaches the most weight.

A formal comparison of these empirical results with those obtained from Day, DeSarbo, and Oliva (1987) is problemsome given the fact that GENFOLD2 derived ideal-point coordinates for the 14 individual firms, while the existing procedure derived them for the five strategic groups. In addition, the present solution estimated dimension weights by strategic group (W), whose analogue was not estimated in Day, DeSarbo, and Oliva (1987). While the first two of the four dimensions estimated here for $\mathrm{X}$ resembles the performance variable space in Day, DeSarbo, and Oliva somewhat, two additional dimensions were obtained. Finally, given the results cited earlier from Ling (1971) and Baker and Hubert (1976), one would have serious difficulties in attempting to define strategic groups from a spatial analysis such as GENFOLD2. 


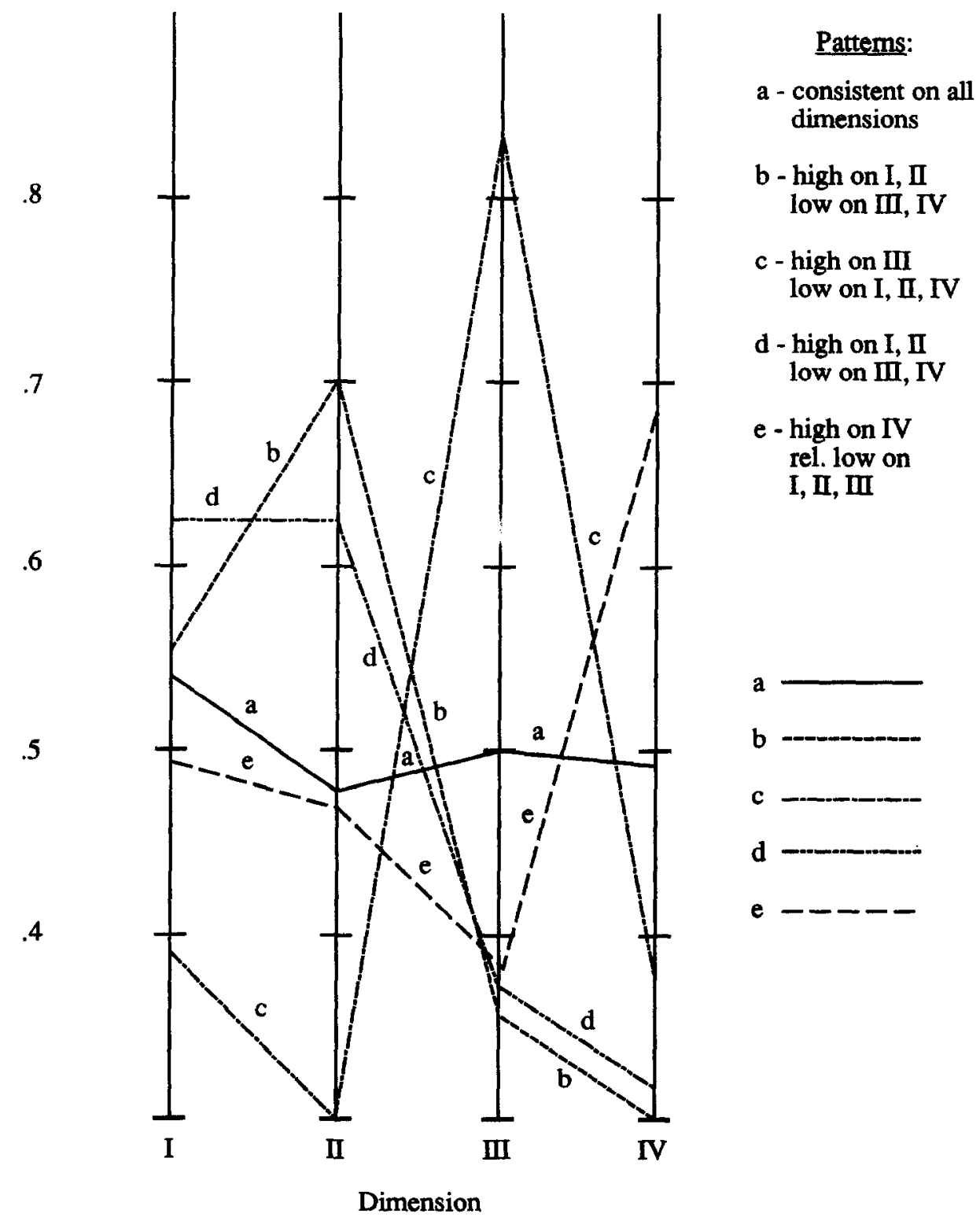

Figure 2. Weights of firm performance. 


\section{References}

Akaike, H. (1974). "A New Look at Statistical Model Identification," IEEE Transactions on Automatic Control 6, 716-723.

Anderberg, M. 1973. Cluster Analysis for Applications. Academic Press, New York.

Arabie, P., J. D. Carroll, and W. S. DeSarbo. (1987). Three-Way Scaling and Clustering. Beverly Hills: Sage Publications.

Baker, F. B., and L. J. Hubert. (1976). "A Graph-Theoretic Approach to Goodness-of-Fit in Complete Link Hierarchical Clustering," Journal of the American Statistical Association 71, 870878.

Bozdogan, H. (1987). "Model Selection and Akaike's Information Criterion (AIC): The General Theory and Its Analytical Extensions," Psychometrika, 52, 345-370.

Bozdogan, H., and S. L. Sclove. (1984). "Multi-sample Cluster Analysis Using Akaike's Information Criterion," Annals of the Institute of Statistical Mathematics 36, 163-180.

Brock, H. H. (1985). "On Some Significance Tests in Cluster Analysis," Journal of Classification 2, 77-108.

Carroll, J. D. (1976). "Spatial, Non-Spatial and Hybird Models for Scaling," Psychometrika 41, $439-463$.

Carroll, J. D. (1980). "Models and Methods for Multidimensional Analysis of Preferential Choice Data," in E. D. Lantermann and H. Feger (eds.), Similarity and Choice. Bern: Hans Huber.

Caves, R. E., and M. E. Porter. (1977). "From Entry Barriers to Mobility Barriers: Conjectural Decisions and Contrived Deterrence to New Competition," Quarterly Journal of Economics 91, $421-441$.

Chang, W. C. (1983). "On Using Principal Components Before Separating a Mixture of Two Multivariate Normal Distributions," Applied Statistics 32, 267-275.

Cool, K., and D. Schendel. (1987). "Strategic Group Formation and Performance: The Case of the U.S. Pharmaceutical Industry, 1963-82," Management Science 33(9), I102-1124.

Cool, K., and D. Schendel. (1988). "Performance Differences Among Strategic Group Members," Strategic Management Journal 9(2), 207-223.

Day, D. L., W. S. DeSarbo, and J. A. Oliva. (1987). "Strategy Maps: A Spatial Representation of Intra-Industry Competitive Strategy," Management Science 33, 1534-1551.

Dempster, A. P., N. M. Laird, and D. B. Rubin. (1977). "Maximum Likelihood From Incomplete Data Via the E-M Algorithm," Journal of The Royal Statistical Society-B 39, 1-38.

DeSarbo, W. S., and V. R. Rao. (1984). "GENFOLD2: A Set of Models and Algorithms for the General Unfolding Analysis of Preference/Dominance Data," Journal of Classification 1, 146-185.

DeSarbo, W. S., and V. R. Rao. (1986). "A New Constrained Unfolding Model for Product Positioning," Marketing Science 5, 1-19.

DeSarbo, W. S., D. Howard, and K. Jedidi. (1991). "MULTICLUS: A New Methodology for Simultaneously Performing Multidimensional Scaling and Cluster Analysis," Psychometrika, forthcoming.

Dess, G., and P. Davis. (1984). "Porter's Generic Strategies as Determinants of Strategic Group Membership and Organizational Performance," Academy of Management Journal 27, 467-488.

Dillon, W. R., Mulani, N., and Frederick, D. G. (1989). "On the Use of Component Scores in the Presence of Group Structure,' Journal of Consumer Research 16, 106-112.

Gnanadesikan, R., and J. R. Kettenring. (1972). "Robust Residuals and Outlier Defection with Multiresponse Data," Biometrics 28, 81-124.

Harrigan, K. R. (1985). "An Application of Clustering for Strategic Group Analysis," Strategic Management Journal 6, 55-73.

Hartigan, J. A. (1975). Clustering Algorithm. New York: John Wiley \& Son.

Hartigan, J. A. (1977). “Distribution Problems in Clustering," in J. Van Ryzin (ed.), Classification and Clustering. New York: Academic Press.

Hartigan, J. A., and P. M. Hartigan. (1985). "The Dip Test of Unimodality," Annals of Statistics $13,70-84$. 
Ling, R. F. (1971). Cluster Analysis. Ann Arbor, MI: University Microfilms, No. 71-22356.

McGee, J., and H. Thomas. "Strategic Groups: Theory, Research and Taxonomy," Strategic Management Journal 7(2), 141-160.

McLachlan, G. J., and K. E. Basford. (1988). Mixture Models: Inference and Applications to Clustering, New York: Marcel Dekkar.

Porter, M. E. (1979). "The Structure Within Industries and Companies' Performance," Review of Economics and Statistics 61, 214-227.

Porter, M. E. (1980). Competitive Strategy. New York: Free Press.

Pruzansky, S., A. Tversky, and J. D. Carroll. (1982). "Spatial Versus Tree Representations of Proximity Data," Psychometrika, 47, 3-24.

Rumelt, R., (1984). "Toward a Strategic Theory of the Firm," in R. Lamb (ed.), Competitive Strategic Management. Englewood Cliffs: Prentice Hall.

Schendel, D. E., and G. P. Patton. (1978). "A Simultaneous Equation Model of Corporate Strategy," Management Science 24, 1611-1621.

Sclove, S. L. (1987). "Application of Model-selection Criteria to Some Problems in Multivariate Analysis," Psychometrika 52, 333-343.

Titterington, D. M., A. F. M. Smith, and V. E. Makov. (1985). Statistical Analysis of Finite Mixture Distributions. New York: John Wiley \& Sons, 1985.

Ward, J. H. (1963). "Hierarchical Grouping to Optimize an Objective Function," Journal of the American Statistical Association 58, 236-244.

White, R. (1986). "Generic Business Strategies, Organizational Context, and Performance: An Empirical Investigation," Strategic Management Journal 7(3), 217-231.

Wilkinson, L. (1988). SYSTAT: The System for Statistics. Evanston, Ill.: SYSTAT, Inc.

Wolfe, J. H. (1970). "Pattern Clustering by Multivariate Mixture Analysis," Multivariate Behavioral Research 5, 329-350. 